\title{
Consumer Adoption of Mobile Services, Discovering the Rules, while Playing the Game
}

Citation for published version (APA):

Kleijnen, M. H. P., de Ruyter, J. C., \& Wetzels, M. G. M. (2004). Consumer Adoption of Mobile Services, Discovering the Rules, while Playing the Game. Journal of Interactive Marketing, 18(2), 51-61. https://doi.org/10.1002/dir.20002

Document status and date:

Published: 01/01/2004

DOI:

10.1002/dir.20002

Document Version:

Publisher's PDF, also known as Version of record

\section{Please check the document version of this publication:}

- A submitted manuscript is the version of the article upon submission and before peer-review. There can be important differences between the submitted version and the official published version of record.

People interested in the research are advised to contact the author for the final version of the publication, or visit the DOI to the publisher's website.

- The final author version and the galley proof are versions of the publication after peer review.

- The final published version features the final layout of the paper including the volume, issue and page numbers.

Link to publication

\footnotetext{
General rights rights.

- You may freely distribute the URL identifying the publication in the public portal. please follow below link for the End User Agreement:

www.umlib.nl/taverne-license

Take down policy

If you believe that this document breaches copyright please contact us at:

repository@maastrichtuniversity.nl

providing details and we will investigate your claim.
}

Copyright and moral rights for the publications made accessible in the public portal are retained by the authors and/or other copyright owners and it is a condition of accessing publications that users recognise and abide by the legal requirements associated with these

- Users may download and print one copy of any publication from the public portal for the purpose of private study or research.

- You may not further distribute the material or use it for any profit-making activity or commercial gain

If the publication is distributed under the terms of Article $25 \mathrm{fa}$ of the Dutch Copyright Act, indicated by the "Taverne" license above, 


\section{CONSUMER ADOPTION OF WIRELESS}

\section{SERVICES: DISCOVERING THE RULES,}

\section{WHILE PLAYING THE GAME}

\author{
MireIIa KIeijnen \\ Ko de Ruy ter \\ Martin Wetzels
}

\section{MIRELLA KLEIJNEN and KO DE RUYTER are members of the Marketing Department, Faculty of Economics and Business \\ Administration at the University of Maastricht, Maastricht, The Netherlands; e-mail: m.kleijnen@mw.unimaas.nl}

MARTIN WETZELS is on the Faculty of Technology Management at the Eindhoven Center for Innovation Studies, Department of Organization Science and Marketing, Eindhoven University of Technology, Eindhoven, The Netherlands.

The authors appreciate Jeanien Werkman's assistance in the data collection for this study.
(C) 2004 Wiley Periodicals, Inc. and

Direct Marketing Educational Foundation, Inc.

JOURNAL OF INTERACTIVE MARKETING VOLUME 18 / NUMBER 2 / SPRING 2004 Published online in Wiley InterScience ( $w w w$.interscience.wiley.com). DOI: $10.1002 /$ dir.20002 


\section{INTRODUCTION}

Wireless or mobile (m-)services have been heralded as the new marketing frontier (Newell \& Newell-Lemon, 2001). This hype was driven by three main factors: the excitement regarding mobile technology; the continuing growth of e-commerce, and the high penetration level of wireless devices worldwide (Shankar, O'Driscoll, \& Reibstein, 2003). Yet, the present market reality is less overpowering than the hype surrounding wireless services. Only small percentages of AT\&T and Sprint wireless customers in the United States are using m-services via their phones, and the continuity of a number of European telecommunication companies is seriously threatened as a result of the exorbitant investments that were paid for the licenses of third-generation (3G) wireless technology (Brodsky, 2001). One of the most important reasons for the disappointing uptake of $\mathrm{m}$-commerce is the failure of firms to understand customer value creation (Shankar et al., 2003). It appears that the added value of wireless services currently being marketed lacks the advantages needed to create a market pull. In fact, it seems that the adoption and diffusion of these services is illustrative of a classic case of technology push (Basso, 2001).

While a plethora of new wireless services has been introduced, mobile gaming services are among the few mobile applications that have been shown to provide a solid business model, and thus might generate revenues needed to finance the heavy expenditure on 3G licenses in Europe (Gold, 2001). While m-gaming has been recognized as a profit generator in itself, with an expected growth of $\$ 950$ million in 2001 to $\$ 17.5$ billion in 2006 worldwide Datamonitor (2000), it furthermore paves the way to create a critical mass needed for the successful integration of more functional-oriented information and transaction services (Sutherland, 2001). Mobile gaming services allow consumers to engage in interactive multiplayer games (MPG) against other remote users regardless of time or location restrictions. To successfully move beyond the technology push and accomplish the adoption of the wireless Web, and wireless gaming in particular, a deeper insight in the factors driving consumers' acceptance of m-services in general and m-gaming in particular is needed.

\section{CONCEPTUAL DEVELOPMENT}

Even though mobile services have received scant attention in academic research thus far, past research does provide a solid foundation for theory development in the area of mobileservice adoption. To analyze the adoption of mobile services, we adopt Rogers' (1995) Adoption of Innovation framework, which has stimulated research and has been validated in various areas (e.g., Au \& Enderwick, 2000). Hereafter, we present a framework that recognizes two central categories that influence adoption-service characteristics and personal characteristics-which is in line with other studies investigating technology adoption (e.g., Dabholkar \& Bagozzi, 2002). Next, we discuss the service characteristics followed by personal characteristics.

\section{Service Characteristics}

Rogers (1995) defined five factors influencing consumers' adoption decisions, of which relative advantage, compatibility, complexity, and communicability are considered in the present study. The last factor defined by Rogers, triabil$i t y$, is not taken into account here as reality demands consumers to invest a substantial amount of time and effort to try mobile services (e.g., personalizing configurations, costs of a hand-held device equipped with technology enabling mobile gaming).

The most obvious relative advantage of mobile services is its ubiquity, which allows consumers to engage in time-killing or stress-relieving activities anywhere and at any time (James, 2001). Compatibility is explained as how well consumers believe mobile services can be integrated in their daily routine. Mobile gaming might fit very well with the behavior of teens, who are used to playing games on other hand-held devices such as Nintendo game systems and who have a fairly good basic knowledge of the Internet (James, 2001). Complexity is associated with the usage of mobile gaming itself (e.g., the ease of grasping the rules of the game) rather than 
the mobile device enabling the services' delivery. Finally, communicability is considered. As defined by Rogers (1995), communicability shows strong resemblance to social influence, which has been recognized as a relevant influential factor by several other research streams (e.g., Fishbein \& Ajzen, 1975), and which in the current context is linked to the interpersonal influences of friends, colleagues, and family (Bhattacherjee, 2000). Participation in mobile gaming might be recognized by consumers as a manner to play a part in a certain social-reference group.

In addition to the Rogers (1995) framework, the current study defines four more factors relevant to consumers' adoption of mobile gaming services: perceived risk, navigation, critical mass, and payment options. Particularly in the current context, perceived risk plays an important role, as the use of highly personalized and context-based technology is particularly prone to consumer risk perception (Newell \& NewellLemon, 2001). We focus particularly on functional risk, which relates to performance (e.g., operator network breakdowns). Furthermore, readings on $\mathrm{m}$-commerce suggest navigation to have a strong impact on a consumer's decision whether to use mobile services (Kaasinen, Aaltone, Kolari, Melakoski, \& Laakko, 2000). Navigation or maneuvering ergonomics associated with the mobile device play a crucial role in network gaming, as it enables the player to react timely to the adversary's actions. Additionally, critical mass is recognized as an essential factor in the decision to adopt mobile services. Interactive innovations in particular (like mobile entertainment services) are relying on the amount of users who have already adopted the innovation (Mahler \& Rogers, 1999). Particularly, the experiential value of mobile gaming is increased with critical mass establishment, as interaction is a major reason for participating (James, 2001).

Payment options is the final factor taken into consideration. Recent studies in the field of $\mathrm{m}$-commerce have indicated that issues related to pricing should not be neglected (e.g., Buellingen \& Woerter, in press). The variety in payment options (e.g., pay-per-use or pay-per- download; Shankar et al., 2003) is creating tremendous price differences that might influence consumers' adoption decisions.

\section{Personality Characteristics}

Hung, $\mathrm{Ku}$, and Chang (in press) stressed the need to investigate consumer traits of potential adopters when studying m-commerce. According to Grewal, Mehta, and Kardes (2000), the success of innovations depends on innovativeness, which introduces the innovation to society, and opinion leadership, which provides social legitimacy to the innovation. Innovativeness is defined as the extent to which an individual or other unit of adoption is early in adopting new ideas relative to other members of a society (Rogers, 1995). Opinion leadership is considered as an important variable in word-of-mouth communication, which contributes to the success of an innovation (Grewal et al., 2000). Here, we take innovativeness as well as opinion leadership into account. Finally, Internet usage was considered as a relevant characteristic. Prior experience with similar products or services might influence the adoption of an innovation (Citrin, Sprott, Silverman, \& Stem, 2000). If a consumer is more inured to gaming on other platforms such as Internet, he or she might be inclined to use mobile devices to play similar games.

\section{RESEARCH DESIGN}

This study has two main objectives: (a) to identify an importance hierarchy concerning the critical factors influencing mobile services adoption and (b) to examine the tradeoffs consumers are willing to make when deciding to actually use mobile services. Conjoint analysis was recognized as an appropriate tool to accomplish these research objectives. The results of the conjoint analysis are employed at the aggregate level for simulations with "hypothetical" mobile service offerings. Finally, we segment the respondents based on the preference structures resulting from the conjoint analysis. 


\section{Measures}

We adopted three constructs as profiling variables for the emergent clusters. Measurement instruments for innovativeness (three items, sample item: "Compared to my friends I have played a lot of mobile games.") and opinion leadership (five items, sample item: "Overall, in all of your discussions with your friends you are often used as a source of advice.") were adopted from Grewal et al. (2000) and adjusted to the specific context of our study. All scales were measured on a 5-point Likert-type scale. Finally, we measured the level of Internet usage by two items: the number of times online (ranging from never to more than once a day) and the average time spent online per day (ranging from 0 to more than $3 \mathrm{hr}$ ). The service characteristics were operationalized by means of scenarios. Each variable was explained by means of a short text and measured on different levels. The levels have not been quantified, yet remained abstract in nature (e.g., high, medium, low). This is in line with similar research in services by, for instance, DeSarbo, Huff, Rolandelli, and Choi (1994), where service quality dimensions are described in scenarios as worse, same, or better than expected. All levels are indicated in Table 1.

\section{Sample}

Pseudorandom sampling was applied to select respondents. A total of 99 respondents were "intercepted" on the street of a midsized city in The Netherlands. To avoid respondent bias (Bush \& Hair, 1985), the research was conducted over a 12-day period that included weekdays and weekend days as well as different hours of the day. This sampling approach allowed us to use personal interviewing, which is preferable given the complexity of the task. The sample can be characterized as follows: gender (female: $52.4 \%$, male: $47.6 \%$ ), age (18-25 years: $42.8 \%$, 26-35 years: $28.6 \%$, >35 years: $28.6 \%$ ), and level of education (at least secondary education: $52.4 \%$; at least tertiary education: $47.6 \%$ ).

\section{ANALYSIS AND RESULTS}

Since the beginning of the 1970 s, the use of (metric) conjoint analysis has gained in popularity both with academics and practitioners (Green \& Srinivasan, 1978). In the present study, we apply Adaptive Conjoint Analysis (ACA; Sawtooth Software, 1997). The partworth utilities obtained from ACA were used to calculate the importance ratings for the eight attributes in the study. Table 1 summarizes the results of the conjoint analysis. Perceived risk is shown to be the most important factor in adopting mobile services $(20.69 \%)$, followed by complexity $(15.19 \%)$, and compatibility $(13.71 \%)$.

\section{Simulations}

We used choice simulations for the further validation of our results (Green \& Srinivasan, 1990). The baseline model matches current mobile-service standards while the alternative models were inspired by $3 \mathrm{G}$ mobile services that are currently being introduced in the Japanese market. Table 2 exhibits various levels of each adoption variable for the baseline and the alternative models.

In the current study, the First Choice Model (FC) and the Share Preference Model (SP) in ACA Version 4.0 were selected for the simulations, both well-established choice rules (Baier \& Gaul, 2001). The results for all simulations are reported in Table 2.

As shown in Table 2, we ran eight simulations against the baseline, changing several of the factors for each. The results of the simulations are in line with our findings. For instance, decreasing perceived risk implies an enormous increase in the intention to adopt (FC $+64.28 \%$, SP $+21.62 \%$ ), indicating the profound impact of perceived risk on the adoption decision that is stronger than any of the other factors. This procedure is repeated for several factors, and every time it confirms our results as generated by the conjoint analysis.

Additionally, we conducted a simulation combining several factors into one alternative model. This alternative model is based on the new 3G mobile services that are currently being introduced in Japan. The alternative model as- 


\begin{tabular}{|c|c|c|c|}
\hline Variable & Level & Importance Ratings & Part-Worth Utilities \\
\hline \multirow[t]{3}{*}{ Perceived Risk } & No risk & $20.69 \%$ & 157.03 \\
\hline & Medium & & 94.58 \\
\hline & High & & 1.55 \\
\hline \multirow[t]{3}{*}{ Relative Advantage } & No relative advantage & $10.50 \%$ & 7.74 \\
\hline & Medium & & 52.35 \\
\hline & High & & 67.78 \\
\hline \multirow[t]{3}{*}{ Compatibility } & Not compatible & $13.71 \%$ & 9.24 \\
\hline & Medium & & 68.51 \\
\hline & High & & 95.83 \\
\hline \multirow[t]{3}{*}{ Complexity } & Low & $15.19 \%$ & 110.154 \\
\hline & Medium & & 78.09 \\
\hline & High & & 1.12 \\
\hline \multirow[t]{3}{*}{ Communicability } & Friends & $8.51 \%$ & 50.05 \\
\hline & Colleagues & & 25.64 \\
\hline & Family & & 24.69 \\
\hline \multirow[t]{3}{*}{ Critical Mass } & Nobody & $9.86 \%$ & 12.09 \\
\hline & Some people & & 52.56 \\
\hline & Many people & & 57.00 \\
\hline \multirow[t]{4}{*}{ Navigation } & Mini-keyboard & $10.73 \%$ & 48.46 \\
\hline & Regular dial buttons & & 26.25 \\
\hline & Dual thumb & & 29.70 \\
\hline & Touch screen & & 66.74 \\
\hline \multirow[t]{3}{*}{ Payment Options } & Minutes online & $10.77 \%$ & 36.04 \\
\hline & Data download & & 41.47 \\
\hline & Flat fee & & 52.29 \\
\hline
\end{tabular}

${ }^{a}$ An earlier version of the preliminary results concerning the conjoint analysis part of the study was presented in B.E. Mennecke \& T.J. Strader (Eds.), Mobile Commerce: Technology, Theory and Applications (pp. 202-217), 2002.

sumes the following characteristics: Mobile services exhibit low perceived risk, high relative advantage, low complexity, a good fit with the consumers' daily activities and prior experiences, and data input handled via touch screens. Introducing mobile services with these characteristics would increase the likelihood that consumers adopt such services tremendously (FC $+80.96 \%$, SP $+50.10 \%$ ). Considering we used $3 \mathrm{G}$ services as a base for our alter- native model, this would imply that $3 \mathrm{G}$ services have a greater chance of being adopted successfully than current WAP applications have been so far.

\section{Cluster Analysis}

The use of cluster analysis to segment respondents on the basis of the results of a conjoint analysis has been widely acknowledged (e.g., Green \& Krieger, 1991). We applied a two-stage 


\section{T A B L E 2}

\section{Results of Simulations}

Baseline model

1. Medium risk

5. Communication with friends

2. Medium relative advantage

6. Critical mass: some people

3. Medium Match with current behavior/prior experiences

7. Input via normal button system

4. Medium level of complexity

8. Payment based on minutes online

RESULTS OF SIMULATION

Choice Model $^{a}$

\begin{tabular}{lcc} 
& & Choice $^{c}$ Model $^{a}$ \\
\cline { 2 - 3 } \multicolumn{1}{c}{ Scenario } & First Choice Model & Share of Preference Model \\
\hline Baseline model & $41.67 \%(5.38)$ & $46.70 \%(1.43)$ \\
Baseline (flat fee) & $58.33 \%(5.38)$ & $53.30 \%(1.43)$ \\
Baseline model & $17.86 \%(4.18)$ & $39.19 \%(1.36)$ \\
Baseline (no risk) & $82.14 \%(4.18)$ & $60.81 \%(1.36)$ \\
Baseline model & $20.24 \%(4.38)$ & $44.40 \%(1.07)$ \\
Baseline (low complexity) & $79.76 \%(4.38)$ & $55.60 \%(1.07)$ \\
Baseline model & $48.81 \%(5.45)$ & $48.91 \%(1.00)$ \\
Baseline (large critical mass) & $51.19 \%(5.45)$ & $51.09 \%(1.00)$ \\
Baseline model & $17.86 \%(4.18)$ & $42.53 \%(1.15)$ \\
Baseline (touch screen) & $82.14 \%(4.18)$ & $57.47 \%(1.15)$ \\
Baseline model & $36.90 \%(5.27)$ & $47.45 \%(1.03)$ \\
Baseline (high relative advantage) & $63.10 \%(5.27)$ & $52.55 \%(1.03)$ \\
Baseline model & $32.14 \%(5.10)$ & $44.86 \%(1.05)$ \\
Baseline (high compatibility) & $67.86 \%(5.10)$ & $55.14 \%(1.05)$ \\
Baseline model & $9.52 \%(3.20)$ & $24.95 \%(2.11)$ \\
Baseline (Extended) ${ }^{b}$ & $90.48 \%(3.20)$ & $75.05 \%(2.11)$ \\
\hline
\end{tabular}

${ }^{\text {a }}$ SEs between brackets.

${ }^{\mathrm{b}}$ No risk, high relative advantage, low level of complexity, high degree of compatibility, input via touch screen.

clustering approach in which a hierarchical algorithm is used to determine the number of clusters, subsequently providing initial cluster seeds for a nonhierarchical algorithm (Punj \& Stewart, 1983). We used Ward's minimum variance method using squared Euclidian distance for the hierarchical cluster analysis. Since there are no completely satisfactory methods to determine the number of clusters in hierarchical cluster analysis, we opted for using multiple methods (Milligan \& Cooper, 1985). We plotted the pseudo $F$ statistic (Calinski \& Harabasz, 1974), the pseudo $t^{2}$ statistic (Duda \& Hart, 1973), and the fusion coefficients against the number of clusters. Inspection of these plots indicated three clusters in the data. Using the fusion coefficients, we calculated the critical value (k) for Mojena's (1977) rule 1 stopping rule, which confirmed the existence of three clusters in the data. In the second stage, the centroids of these three clusters were employed as starting seeds for a k-means clustering algorithm. We obtained three clusters with respectively 19, 39, and 26 observations.

\section{Cluster Characteristics}

We used the clustering variables, the profiling variables (not used in the clustering procedure), opinion leadership, and innovativeness as well as Internet usage and the demographic variables to characterize the three clusters. Initially, we employed sequential multinomial lo- 
gistic regression, with cluster membership as the dependent variable and with the three profiling variables and the demographic variables as independent variables (DeMaris, 1992; Hosmer \& Lemeshow, 2000).

A $\chi_{\mathrm{LR}}^{2}$ difference test was calculated on the basis of the difference between the $-2 \log$ likelihood for a restricted model $\left[-2 \mathrm{LL}\left(\mathrm{D}_{0}\right)\right]$ and the -2 maximized log-likelihood for an unrestricted model $\left[-2 \mathrm{LL}\left(\mathrm{D}_{\mathrm{M}}\right)\right]$. The full model contains all the profiling variables: opinion leadership, innovativeness, Internet usage, and the demographic variables [specified as indicator variables: AGE $(18-25=0,>25=1)$, GENDER ( male $=1$, female $=0$ ), and EDUCATION (at least secondary level $=0,>$ secondary level $=1$ )] as independent variables whereas the restricted model contains only opinion leadership, innovativeness, and Internet usage as independent variables. The $\chi_{\mathrm{LR}}^{2}$ difference test indicated, $\Delta \chi^{2}(6)=7.31, p=0.29$, that the demographic variables do not significantly contribute to the explanatory power of the model (cf. Simonoff, 1998). Therefore, we used the reduced model containing only opinion leadership, innovativeness, and Internet usage as independent variables. The model fit of the reduced model is adequate. The hypothesized model differs significantly from the intercept model, $\Delta \chi^{2}(6)=22.25, p<0.001$, and showed an adequate model fit in terms of the pseudo $R^{2}$ statistics (Cox \& Snell's $R^{2}=0.23$; Nagelkerke's $\left.R^{2}=0.27\right)$. Inspecting the results of the likelihood ratio test statistic for the independent variables in the hypothesized model revealed that apart from the intercept, $\chi_{\mathrm{LR}}^{2}=14.98, p$ $=0.001$, innovativeness, $\chi_{\mathrm{LR}}^{2}=9.19, p=0.010$, and Internet usage, $\chi_{\mathrm{LR}}^{2}=6.51, p<0.039$, exhibited a significant effect $(\alpha=0.05)$ on cluster membership. The parameter estimates and the accompanying Wald statistic indicated significant effects $(\alpha=0.05)$ for Cluster $1(n$ $=19)$ versus Cluster $3(n=26)$ for innovativeness $(\mathrm{B}=0.929$, Wald $=6.33, p=0.012$, odds ratio $=5.220)$ and Internet use $(\mathrm{B}=0.939$, Wald $=5.401, p=0.020$, odds ratio $=5.646)$. For Cluster $1(n=19)$ versus Cluster $2(n=39)$, we found a significant effect $(\alpha=0.05)$ for innovativeness $(\mathrm{B}=0.867$, Wald $=6.948$, $p=0.008$, odds ratio $=4.534)$.

Table 3 shows the descriptive statistics for the clustering and the profiling variables. We tested for differences among the clusters for the cluster variables, which are included in the cluster analysis. We used the Games and Howell (1976) procedure for pairwise comparisons. This procedure maintains the family-wise error rate close to the chosen $\alpha$ for equal and unequal variances and equal and unequal sample sizes (Toothaker, 1992). Except for critical mass, all other attributes show statistically significant differences among the clusters, as can be observed from the $F$ statistic and the pairwise comparisons.

Exploratory factor analysis was used for construct validation of the three profiling variables. Adopting principal factoring with oblique rotation with Kaiser normalization (extracting three factors), we found that the items in the pattern matrix loaded high on their respective hypothesized factors (opinion leadership: 0.64-0.87, innovativeness: $0.58-0.82$, Internet usage: $0.78-0.80)$ and exhibited relatively small loadings for the other factors.

Table 4 contains the means, $S D$ s, intercorrelations, and coefficients alpha for the profiling variables. The reliabilities in terms of coefficient alpha all exceed the recommended cutoff value of 0.7 (Nunnally \& Bernstein, 1994). Next, the profiling variables were used to test for differences among the clusters. Similarly, we used the Games and Howell (1976) procedure for pairwise comparisons. These results are depicted in Table 3.

For the first cluster, communicability, payment options, and navigation appear to be the most important. These technology characteristics are all strongly related to game playing. Therefore, this cluster is specified as "Game Players." Furthermore, the respondents in this cluster distinguish themselves by expressing a significantly higher level of innovativeness. In the second cluster, labeled "Value Seekers," consumers focus on the additional value in using mobile services and the fit to their current living style and value system. In the final cluster, perceived risk as well as complexity are promi- 
T A B L E 3

Cluster Characteristics

\begin{tabular}{|c|c|c|c|c|c|c|c|}
\hline \multirow[b]{2}{*}{ Cluster Variables } & \multicolumn{5}{|c|}{ Importance Ratings (\%) ${ }^{a}$} & \multicolumn{2}{|c|}{ Test } \\
\hline & Game Players $(\mathrm{n}=19)$ & Value Seekers $(\mathrm{n}=39)$ & \multicolumn{3}{|c|}{ Risk Avoiders $(\mathrm{n}=26)$} & $\mathrm{F}(2,81)$ & $\mathrm{p}$ \\
\hline Perceived Risk & $14.52^{\mathrm{A}}$ & $18.08^{\mathrm{B}}$ & \multicolumn{3}{|c|}{$29.14^{\mathrm{C}}$} & 45.918 & $<.001$ \\
\hline Relative Advantage & $9.59^{\mathrm{A}}$ & $13.16^{\mathrm{B}}$ & \multicolumn{3}{|c|}{$7.20^{\mathrm{A}}$} & 9.040 & $<.001$ \\
\hline Comparability & $9.59^{\mathrm{A}}$ & $17.93^{\mathrm{B}}$ & \multicolumn{3}{|c|}{$10.40^{\mathrm{A}}$} & 23.727 & $<.001$ \\
\hline Complexity & $13.00^{\mathrm{A}}$ & $13.77^{\mathrm{A}}$ & \multicolumn{3}{|c|}{$18.93^{\mathrm{B}}$} & 7.708 & .001 \\
\hline Communicability & $15.51^{\mathrm{A}}$ & $6.71^{\mathrm{B}}$ & \multicolumn{3}{|c|}{$6.13^{\mathrm{B}}$} & 22.743 & $<.001$ \\
\hline Critical Mass & 8.49 & 10.89 & \multicolumn{3}{|c|}{9.34} & 1.234 & .297 \\
\hline Navigation & $15.16^{\mathrm{A}}$ & $9.64^{\mathrm{B}}$ & \multicolumn{3}{|c|}{$9.13^{\mathrm{B}}$} & 7.095 & .001 \\
\hline Payment Options & $14.15^{\mathrm{A}}$ & $9.82^{\mathrm{B}}$ & \multicolumn{3}{|c|}{$9.75^{\mathrm{B}}$} & 6.491 & .002 \\
\hline \multirow[b]{2}{*}{ Profiling Variables } & & & & & \multicolumn{3}{|c|}{ Test } \\
\hline & \multicolumn{2}{|r|}{ Mean Scores } & \multicolumn{4}{|c|}{$\mathrm{F}(2,81)$} & $\mathrm{p}$ \\
\hline Opinion Leadership & 3.40 & 3.33 & \multicolumn{2}{|l|}{2.95} & \multicolumn{2}{|l|}{1.838} & 0.166 \\
\hline Innovativeness & $4.42^{\mathrm{A}}$ & $3.55^{\mathrm{B}}$ & \multicolumn{2}{|l|}{$3.12^{\mathrm{B}}$} & \multicolumn{2}{|l|}{7.215} & 0.001 \\
\hline Internet Usage & $3.97^{\mathrm{A}}$ & $3.57^{\mathrm{A}}$ & \multicolumn{2}{|l|}{$3.02^{\mathrm{B}}$} & \multicolumn{2}{|l|}{5.976} & 0.004 \\
\hline
\end{tabular}

${ }^{a}$ Identical superscripts indicate no statistically significant differences at $\alpha=0.05$ using the Games and Howell (1976) procedure for pairwise comparisons.

nently present. The consumers in this cluster will use mobile services only if they are sure that these will be delivered as promised. Accordingly, the importance of complexity might be explained by the fact that increased complexity will make it difficult for the consumer to deliver the proper input, which also can result in mobile services not living up to the expectations of the customer. Additionally, note that consumers in this particular cluster can be characterized by a low level of Internet usage. This cluster is referred to as "Risk Avoiders."

\section{MANAGERIAL IMPLICATIONS}

Several managerial implications can be derived. The findings explicate a substantial influence of perceived risk on the mobile service adoption process. Consequently, a predominant focus on risk reduction and m-trust creation is imperative for successful establishment of mobile services. Companies need to invest in systems that assure reliable and secure data transmission, prohibiting bad system performance as well as misuse/abuse of personal information $(\mathrm{Ny}-$

T A B L E 4

Means, SDs, and Intercorrelations of Profiling Variables ${ }^{\mathrm{a}}$

\begin{tabular}{|c|c|c|c|c|c|}
\hline Constructs & M & SD & 1. & 2. & 3. \\
\hline 1. Opinion Leadership & 3.23 & 0.92 & $0.85^{\mathrm{b}}$ & & \\
\hline 2. Innovativeness & 3.61 & 1.23 & 0.53 & 0.87 & \\
\hline 3. Internet Use & 3.49 & 0.98 & 0.27 & 0.37 & 0.91 \\
\hline
\end{tabular}

a All intercorrelations are significant at $\alpha=0.05$.

${ }^{\mathrm{b}}$ Coefficient alpha on the diagonal. 
shadham, 2000). Additional implications arise from the customer profiles that have been identified, providing marketers the opportunity to segment the market and to target each segment in a unique way. Several recommendations can be formulated with respect to the identified segments. For Game Players, it is important to improve navigation systems, especially in m-entertainment but also in other service categories. Recently navigation and design aspects are receiving increased attention, and several device producers are offering additional features to improve mobile navigation such as mobile joysticks. Another important factor is payment options (e.g., subscription-based service usage). This factor is expected to become more ubiquitous with the introduction of new wireless technologies as it leads to less insecurity regarding service prices. Game Players also distinguish communicability as a relevant technology characteristic. Increasing visibility of mobile services can be accomplished by providing communities or buddy list options enabling customers a convenient channel to inform their peers or invite them to join for a game. Finally, Game Players discriminate themselves from other segments through a higher level of innovativeness. Stressing the novelty of mobile services in advertising and providing exclusive access to new games before market introduction might be useful tools for marketers in reaching these customers.

Value Seekers concentrate on the relative advantage of mobile services and the compatibility to daily lifestyle as essential adoption criteria. Consequently, companies need to focus on the unique advantages of mobile services, thereby not only stressing ubiquity of m-commerce but also pointing out the opportunities of localization and personalization. The latter are expected to pop up with the introduction of $3 \mathrm{G}$ technologies.

Finally, Risk Avoiders mainly focus on perceived risk, but complexity also is of significant importance. This illustrates a need for information on m-services usage. This need is confirmed by the fact that Risk Avoiders show a significantly lower level of Internet usage, indicating less experience with technology. Marketers can provide this usage information through various channels. Furthermore, the usage of relatively uncomplicated services should be stimulated. Customer acquaintance to this category of m-services also will lower the barrier to exploit other m-services.

\section{LIMITATIONS AND SUGGESTIONS FOR FURTHER RESEARCH}

Part of the strength of a study lies in the acknowledgment of its limitations. These limitations lead to suggestions for future research and elucidate theoretical implications. First, despite a thorough literature review, we might have overlooked relevant variables. One additional variable that deserves particular attention in further research is price, especially considering the attention that has been devoted to this factor in recent studies on wireless commerce (e.g., Hung et al., in press). While the current research has made an attempt to include a related variable (payment options), further research should explicitly account for the effect of price.

Additionally, further validation of the use of abstract attributes such as relative advantage and compatibility is necessary. Conjoint studies typically include concrete product or service features that are fairly easily manipulated by researchers and easily understood by consumers. Although other research in this area has validated these manipulations in an experimental setting (de Ruyter, Wetzels, \& Kleijnen, 2001), the operationalization of these constructs by defining more concrete aspects that constitute, for example, relative advantage would enhance the validity of the study. Furthermore, the study was conducted in The Netherlands, which might imply limited external validity of the results to countries where uptake of mobile commerce has been anticipated to be faster and more widespread. Moreover, the sample size was rather small. Although Green and Srinivasan (1990) stated that conjoint analysis applied on an individual level is not extremely dependent on the sample size, the external validity of the results might be limited. A further limitation in this realm is the contextual setting of our study. Given the fact 
that our research was embedded in a mobilegaming context, the external validity of the obtained results is not guaranteed for differing types of mobile services. For future research, we recommend that our results should be cross validated using multiple methods, additional samples, and contexts.

\section{CONCLUSIONS}

Several conclusions result from the current study. Conjoint analysis as well as the conducted simulations allowed us to identify perceived risk, complexity, and compatibility as the three main adoption factors. In this realm, the most imperative motivation for not engaging in a wireless transaction is risk (Newell \& NewellLemon, 2001). For wireless, the level of customer intimacy is even greater than for wired transactions, whereby the role of security and privacy issues are of crucial importance. Complexity of current mobile services forms another impediment. Despite the fact that one of the primary objectives of m-commerce is to simplify life for consumers (Koranteng, 2000), many first-time users find the ease-of-use of current mobile service far below desired levels of comprehension. Finally, compatibility of mobile gaming to consumers' lifestyle needs more attention. Although mobile phone penetration is high, consumers do not recognize how the use of mobile services can fit their lives. Critical mass and communicability appear to have the least influence. These factors relate to social aspects associated with mobile services and mobile gaming particularly. Yet, our results indicate that for the time being, m-commerce is mainly considered as a personal technology. Finally, cluster analysis resulted in a three-cluster solution, identifying Internet usage and innovativeness as discriminating characteristics between clusters, which offers possibilities to segment customers consistent with their needs and fine tune company strategies accordingly.

\section{REFERENCES}

Au, A.K., \& Enderwick, P. (2000). A Cognitive Model on Attitude Towards Technology Adoption. Journal of Managerial Psychology, 15(4), 266-282.
Baier, D., \& Gaul, W. (2001). Marketing Simulations Using a Probabilistic Ideal Vector Model for Conjoint Data. In F. Heber (Ed.), Conjoint Measurement: Methods and Applications (2nd ed., pp. 96120). Berlin: Springer-Verlag.

Basso, M. (2001). Mobile Portals: Five Critical Success Factors. ZDNet Wireless Update.

Bhattacherjee, A. (2000). Acceptance of E-Commerce Services: The Case of Electronic Brokerage. IEEE Transactions of Systems, Man and Cybernetics, 30(4), 411-420.

Brodsky, I. (2001). Europe's Wireless Industry Is on the Brink of Disaster. Network World Fusion.

Buellingen, F., \& Woerter, M. (in press). Development Perspectives, Firm Strategies and Applications in Mobile Commerce. Journal of Business Research.

Bush, A.J., \& Hair, J.F., Jr. (1985). An Assessment of the Mall Intercept as a Data Collection Method. Journal of Marketing Research, 32(November), 385-391.

Calinski, R.B., \& Harbasz, J. (1974). A Dendrite Method for Cluster Analysis. Communications in Statistics, 3, $1-27$.

Citrin, A.V., Sprott, D.E., Silverman, S.N., \& Stem, D.E., Jr. (2000). Adoption of Internet Shopping: The Role of Consumer Innovativeness. Industrial Management \& Data Systems, 100(7), 294-300.

Dabholkar, P.A., \& Bagozzi, R.P. (2002). An Attitudinal Model of Technology-Based Self-Service: Moderating Effects of Consumer Traits and Situational Factors. Journal of the Academy of Marketing Science, 30(3), 184-201.

Datamonitor. (2000, September 6). The Future of Wirless Gaming. Retrieved May 2001 from http://www. datamonitor.com

DeMaris, A. (1992). Logit Modelling: Practical Applications. Newbury Park, CA: Sage.

de Ruyter, K., Wetzels, M.G.M., \& Kleijnen, M.H.P. (2001). Customer Adoption of E-Services: An Experimental Study. International Journal of Service Industry Management, 12(2), 184-207.

DeSarbo, W.S., Huff, L., Rolandelli, M.M., \& Choi, J. (1994). On the Measurement of Perceived Service Quality. In R.L. Oliver (Ed.), Service Quality (pp. 201-222). Thousand Oaks, CA: Sage.

Duda, R.O., \& Hart, P.E. (1973). Pattern Classification and Scene Analysis. New York: Wiley.

Fishbein, M., \& Ajzen, I. (1975). Belief, Attitude, Intention and Behavior. Reading, MA: Addison-Wesley.

Games, P.A., \& Howell, J.F. (1976). Pairwise Multiple Comparison Procedures with Unequal N's and/or Variances. Journal of Educational Statistics, 1, 113125 . 
Gold, S. (2001). Mobile Gaming: Savior of Europe's Wireless Nets? Newsbytes.

Green, P.E., \& Krieger, A.M. (1991). Segmenting Markets with Conjoint Analysis. Journal of Marketing, 55(October), 20-31.

Green, P.E., \& Srinivasan, V. (1978). Conjoint Analysis in Consumer Research: Issues and Outlook. Journal of Consumer Research, 5(September), 103-123.

Green, P.E., \& Srinivasan, V. (1990). Conjoint Analysis in Marketing: New Developments with Implications for Research and Practice. Journal of Marketing, 4, 3-19.

Grewal, R., Mehta, R., \& Kardes, F.R. (2000). The Role of the Social-Identity Function of Attitudes in Consumer Innovativeness and Opinion Leadership. Journal of Economic Psychology, 21, 233-252.

Hosmer, D.W., \& Lemeshow, S. (2000). Applied Logistic Regression (2nd ed.). New York: Wiley.

Hung, S.-Y., Ku, C.-Y., \& Chang, C.-M. (in press). Critical Factors for the Adoption of WAP Services: An Empirical Study. Electronic Commerce Research and Applications.

James, J. (2001). Mobile Gaming: An Introduction to the Mobile Gaming Market. Mobile Streams Ltd. Retrieved September 1, 2001, from http:// www.games4mobile.com/pdf/gaming.pdf

Kaasinen, E., Aaltone, M., Kolari, J., Melakoski, S., \& Laakko, T. (2000). Two Approaches to Bringing Internet Services to WAP Devices. Computer Networks, 33, 231-246.

Koranteng, X. (2000). Dial "M" for E-Commerce. Advertising Age International, May, 1-24.

Mahler, A., \& Rogers, E.M. (1999). The Diffusion of Interactive Communication Innovations and the Critical Mass: The Adoption of Telecommunication
Services by German Banks. Telecommunications Policy, 23, 719-740.

Milligan, G.W., \& Cooper, M.C. (1985). An Examination of Procedures for Determining the Number of Clusters in a Data Set. Psychometrika, 50, 159-179.

Mojena, R. (1977). Hierarchical Grouping Methods and Stopping Rules: An Evaluation. Computer Journal, 20, 359-363.

Newell, F., \& Newell-Lemon, K. (2001). Wireless Rules. New York: McGraw-Hill.

Nunnally, J.C., \& Bernstein, I.H. (1994). Psychometric Theory. New York: McGraw-Hill.

Nyshadham, E.A. (2000). Privacy Policies of Air Travel Web Sites: A Survey and Analysis. Journal of Air Transport Management, 6, 143-152.

Punj, G., \& Stewart, D.W. (1983). Cluster Analysis in Marketing Research: Review and Suggestions for Application. Journal of Marketing Research, 20(May), 134-148.

Rogers, E.M. (1995). Diffusion of Innovations (4th ed.). New York: Free Press.

Sawtooth Software. (1997). ACA System 4.0 Manual. Sequim, WA: Sawtooth Software, Inc.

Shankar, V., O'Driscoll, T., \& Reibstein, D. (2003). Rational Exuberance: The Wireless Industry's Killer B. Strategy \& Business, 31(Summer), 68-77.

Simonoff, J.S. (1998). Logistic Regression, Categorical Predictors, and Goodness-of-Fit: It Depends on Who You Ask. American Statistician, 52(1), 10-15.

Sutherland, E. (2001). Wireless Gaming. M-Commerce Times. Retrieved September 2002 from http://www. mcommercetimes.com

Toothaker, L.E. (1992). Multiple Comparison Procedures. Newbury Park, CA: Sage. 